\title{
laborhifórico
}

ISSN 2359-6910

https://revistas.ufrj.br/index.php/lh/

ARTIGO

Recebido em 22 de agosto de 2019

Aprovado em 30 de setembro de 2019

\section{A carta de Françisca Maria Xavier de Castro: edição e reflexões sobre o imaginário social de mulheres na América Portuguesa}

\begin{abstract}
The letter from Françisca Maria Xavier de Castro Castro: edition and reflections on the social imaginary of women in Portuguese America
\end{abstract}

DOI: https://doi.org/10.24206/1h.v5i2.29110

Elisa Hardt Leitão Motta

Cursa bacharelado e licenciatura em Letras Português-Francês na Universidade de São Paulo. Foi bolsista na mesma instituição pelo Programa Unificado de Bolsas de Estudo da Pró-Reitoria de Graduação e, atualmente, é pesquisadora e bolsista no Projeto M.A.P. (Mulheres na América Portuguesa).

E-mail: elisa.hardt.motta@usp.br ORCID: https://orcid.org/0000-0001-5568-5957

\section{Vanessa Martins do Monte}

Possui mestrado e doutorado em Filologia e Língua Portuguesa pela Universidade de São Paulo (2007 e 2013). É coordenadora do NEHiLP Núcleo de Apoio à Pesquisa em Etimologia e História da Língua Portuguesa - e do Projeto M.A.P. - Mulheres na América Portuguesa. Atua como docente na Faculdade de Filosofia, Letras e Ciências Humanas (FFLCH) da USP. Tem experiência nas áreas de Filologia, Paleografia, Codicologia, História da Língua Portuguesa e Humanidades Digitais. Concilia sua carreira profissional com a maternidade de um filho pequeno. É também madrasta de dois enteados jovens.

E-mail: vmmonte@usp.br

ORCID: https://orcid.org/0000-0002-4929-5298 


\section{RESUMO}

A edição e as reflexões aqui apresentadas surgem como um dos resultados do processo de prospecção de documentos no Arquivo Público do Estado de São Paulo (APESP) no contexto do Projeto M.A.P. - Mulheres na América Portuguesa. As visitas de prospecção tiveram por propósito a contribuição para a ampliação do mapeamento de documentos escritos por mulheres ou nos quais mulheres figurem em posição central durante a América Portuguesa (1500-1822). A partir da prospecção das pastas do fundo da Secretaria de Governo da Capitania de São Paulo, localizado no APESP, e da subsequente leitura e seleção de quatro documentos pertinentes dentro da pasta identificada como 1.1.697, foram realizados o registro e a catalogação desses documentos, bem como a edição semidiplomática e as análises diplomáticas, paleográficas e codicológicas. Para este artigo, elegeu-se a carta identificada com o número 23, escrito a lápis no recto do primeiro fólio, de autoria de Françisca Maria Xavier de Castro. Durante o processo de edição, foi possível levantar hipóteses sobre o contexto histórico e social da autora. Alfabetizada, dona de pessoas escravizadas e responsável pelas próprias finanças, Françisca Maria Xavier de Castro pode ser vista como um desvio da imagem criada com base em estereótipos reproduzidos pela historiografia e que caracteriza a mulher branca como sempre submissa e ausente, tanto das relações sociais em comunidade como das decisões econômicas dentro do próprio lar. São apresentadas as edições fac-similar, semidiplomática e modernizada do documento. Além disso, propõe-se um conjunto de normas para a edição modernizada.

Palavras-chave: História das mulheres. América Portuguesa. Filologia. Paleografia. Edição.

\section{ABSTRACT}

The edition and the reflections presented here appear as one of the results of the process of prospection of documents in the Public Archive of the State of São Paulo (APESP) in the context of the M.A.P Project - Women in Portuguese America. The prospecting visits were intended to contribute to broadening the mapping of documents written by women or documents written about women (containing their 'speech' in the form of reported discourse) during Portuguese America (1500-1822). From the prospecting of the folders of the fund of the Secretariat of Government of the Captaincy of São Paulo, located in APESP, and the subsequent reading and selection of four pertinent documents within the folder identified as 1.1.697, these documents were registered and cataloged. It was also made their semidiplomatic edition and the diplomatic, paleographic and codicological 
analyzes. For this article, we chose the letter identified with number 23, written by Françisca Maria Xavier de Castro. During the editing process, it was possible to raise hypotheses about the author's historical and social context. Literate, owner of enslaved people and responsible for her own finances, Françisca Maria Xavier de Castro can be seen as a deviation from the image created based on stereotypes reproduced by historiography. This image characterizes the white woman as always submissive and absent, both from social relations in the community, as well as from economic decisions within one's own home. The facsimile, semidiplomatic, and modernized editions of the document are presented. In addition, a set of standards for the modernized edition is proposed.

Keywords: History of women. Portuguese America. Philology. Paleography. Edition. 


\section{Introdução}

No dia 8 de maio do ano de 1791, na Capitania de São Paulo, Françisca Maria Xavier de Castro escreve uma carta endereçada a Francisco Ioze de Souza. 228 anos depois, o documento foi descoberto, e seu conteúdo, lido, transcrito, analisado e editado por uma graduanda da Faculdade de Filosofia, Letras e Ciências Humanas da USP. Os resultados deste trabalho de pesquisa ${ }^{1}$ são expostos neste breve texto.

O documento em questão foi encontrado no âmbito das pesquisas do Projeto M.A.P. - Mulheres na América Portuguesa ${ }^{2}$, em uma visita para prospecção de documentos no Arquivo Público do Estado de São Paulo (APESP) ${ }^{3}$. O projeto, coordenado pelas professoras Maria Clara Paixão de Sousa e Vanessa Martins do Monte, reúne uma documentação dispersa e de difícil acesso em um catálogo eletrônico online ${ }^{4}$. Como o título já informa, o objetivo do projeto consiste em um mapeamento de documentos de diversas tipologias (cartas, bilhetes, processos, autos etc.) que tenham sido ou escritos por mulheres ou em que as mulheres figurem em posição central durante o período da América Portuguesa, entre o século XVI e o início do século XIX.

Uma das campanhas mais recentes de prospeção documental do Projeto M.A.P. concentrou-se nas pesquisas no fundo da Secretaria de Governo da Capitania de São Paulo, salvaguardadas pelo APESP. A pasta prospectada, de número 1.1.697, apresenta 115 documentos e tem como título "Ofícios, ordens, requerimentos e certificados". Seu conteúdo é descrito no guia do acervo ${ }^{5}$ online da seguinte forma:

Ofícios e cartas das câmaras de Santana do Parnaíba, Santos, São Paulo, Cuiabá, Sorocaba, São Sebastião, Ubatuba e Taubaté. Contêm ofícios, requerimentos de provisões, editais, relações de despesas das câmaras, cartas de confirmação e usança, correspondência entre as câmaras de São Paulo e Parnaíba, certificados de realização de ofícios religiosos e instruções para os capitães mores. Ofícios sobre o Hospital Militar,

\footnotetext{
${ }^{1}$ A primeira versão deste texto foi elaborada para o trabalho final da disciplina optativa livre Filologia do Português: Edição de documentos brasileiros, ministrada pela Prof ${ }^{a}$ Dr $^{a}$ Vanessa Martins do Monte, no primeiro semestre de 2019, no Instituto de Estudos Brasileiros da USP. Aproveitamos para agradecer a gentileza e a constante disponibilidade da equipe do Arquivo do IEB, em especial à Denise de Almeida Silva, supervisora técnica do serviço de Arquivo, e à Elisabete Marin Ribas, funcionária do Arquivo.

${ }^{2}$ O Projeto M.A.P. pode ser acessado pelo endereço eletrônico map.prp.usp.br

${ }_{3}^{3}$ Aproveitamos para agradecer ao diretor do Centro de Acervo Permanente do APESP, Marcelo Thadeu Quintanilha, que nos tem auxiliado imensamente e incentivado as visitas de prospeção das pesquisadoras do Projeto M.A.P. Mulheres na América Portuguesa.

${ }^{4}$ PAIXÃO DE SOUSA, M. C.; MONTE, V. M. do et al. Projeto M.A.P. (Mulheres na América Portuguesa): Mapeamento de escritos de mulheres e sobre mulheres no espaço atlântico português a partir de métodos das Humanidades Digitais. Disponível em: <http://nehilp.prp.usp.br/ nehilp/HD/MAP/>. Acesso em: 28 de setembro de 2019.

Guia do Acervo do Arquivo Público do Estado de São Paulo. Disponível em: <http://icaatom. arquivoestado.sp.gov.br/ica-atom/index.php/oficios-ordens-requerimentos-e-certificados;isad>. Acesso em: 17 de maio de 2019 .
} 
lista de doação de fardamento para as tropas em marcha para o Uruguai, preços das fardas, distribuição de carne e penhora de bens. Ofício sobre o fracasso da povoação de Casa Branca, do plano de conquista e povoação do Oeste do Paraná e uma lista do ouro encaminhado ao Rio de Janeiro (1787). Mapas de população de São Paulo, Santo Amaro, Guarulhos, Jacareí, São José e suas freguesias (1792) e uma cópia de uma escritura de doação de terras do general Arouche.

O fundo da Secretaria de Governo da Capitania é composto por documentos produzidos pelas autoridades do reino, da colônia e da capitania. Há também documentos particulares solicitando perdão, auxílio e mercês. O conteúdo deste fundo é formado por documentos de assuntos e tipologias diversificados, mas todos no âmbito da administração da capitania.

Dentre estes 115 documentos que pertencem à referida pasta $n^{\circ}$ 1.1.697 do fundo da Secretaria de Governo da Capitania de São Paulo, datados entre 1781 e 1826, em somente quatro constam nomes de mulheres. Desses quatro documentos, em somente dois as mulheres são autoras. Selecionamos um deles para transcrever, editar e analisar algumas de suas características diplomáticas, paleográficas e codicológicas. Trata-se da carta escrita por Françisca Maria Xavier de Castro em 8 de maio do ano de 1791. A partir da análise inicial, pode-se fazer uma conjectura a respeito de sua classe social: Françisca possuía um lugar elevado na sociedade paulista do final do século XVIII e tinha controle sobre as suas finanças, destoando, portanto, de uma certa visão construída da mulher branca do Brasil no período colonial como a esposa ${ }^{6}$ sempre ociosa e submissa que ficava restrita aos ambientes privados.

Por tratar-se de um documento escrito por uma mulher durante a América Portuguesa, é interessante incluir aqui uma breve contextualização das condições da educação e da inserção feminina na cultura escrita durante este período. Vartuli (2012, p. 35) afirma que "no que respeita às práticas educativas no período colonial, relacionadas ao universo feminino, percebemos certo silêncio historiográfico", fato que dificulta imensamente a pesquisa nessa área. Esse desfoque - e, por vezes, exclusão - da presença e da importância feminina na constituição da sociedade colonial será retomado na próxima seção. Vartuli (2012) salienta que apesar de a educação não ser, de forma geral, uma constante na vida das mulheres, diferentes formas de aprendizagem fizeram parte do cotidiano delas por meio da circulação de saberes em outros espaços. É possível que este tenha sido o caso de Françisca.

Por fim, é importante estabelecermos que o objetivo deste texto não é o de estender-se em um levantamento profundo sobre o contexto histórico e social de Françisca, ou ainda, sobre a história da educação no período colonial. Iremos, apenas, apresentar uma breve descrição do contexto histórico e estabelecer reflexões e comentários que podem ser tecidos a partir da descrição dos aspectos

\footnotetext{
${ }^{6} \mathrm{Na}$ carta não há, inclusive, qualquer menção a maridos ou filhos.
} 
diplomáticos, paleográficos e codicológicos da carta em tela. Chamamos atenção, principalmente, para o fato de a autora do documento ser alfabetizada e ter controle da administração da indústria doméstica $^{7}$ em um período histórico onde isso era considerado raro. Ademais, acompanha a edição semidiplomática e fac-similar a proposta de uma edição modernizada do documento analisado.

\section{As mulheres no imaginário social da América Portuguesa}

Ainda hoje, a imagem acerca das mulheres brancas que habitavam a Capitania de São Paulo construída no imaginário social é frequentemente a de mulheres recatadas, passivas, submissas e ociosas, com nenhuma ou poucas funções dentro do lar. Tal fato ilustra a força da influência de uma historiografia enviesada. Wolff e Possas (2005, p. 585) iniciam seu texto afirmando que a exclusão das mulheres de narrativas produzidas por historiadores ocorre devido ao fato de elas, por muito tempo, não terem sido consideradas sujeitos da história.

Em um artigo para a Revista de História (1983, p. 39-41), Maria da Silva Dias, uma das precursoras do estudo da história das mulheres no Brasil, relaciona essa "incapacidade de tratar da participação de mulheres no processo de formação da sociedade brasileira" a uma tradição misógina que esteve "fortemente entranhada" na cultura da colônia e que foi perpetuada através de costumes tradicionais. O contato com documentos carregados de juízos de valor e de referências genéricas fez com que vários historiadores não conseguissem se desvencilhar de idealidades e estereótipos, impedindo que vissem com maior clareza o contexto histórico de que tratavam. Esse fenômeno é observado até mesmo em trabalhos cujo objeto de análise é especificamente o universo das mulheres. O resultado disso, segundo a autora, foi a persistência de uma "sombra do simbólico e das alegorias, sob a forma do conceito de condição feminina e certa insistência nos mitos da mulher" (DIAS, 1983, p. 41). Dias (1983) explica também que a ausência de documentos oficiais ou de romances urbanos que relatassem as mulheres solteiras e chefes de fogos improvisando o "ganha pão" ocorreu por tratarse "de ocupações desairosas, a serem caladas, por evocar justamente o reverso dos papéis sociais normativos atribuídos às mulheres, que pressupunham hábitos de clausura, resguardo e distância social” (DIAS, 1983, p. 38).

A década de 80 assiste a um esforço coletivo de historiadoras brasileiras em torno dos estudos sobre a história das mulheres na sociedade colonial. Essas pesquisas fundam um novo campo de investigação que será alimentado pela descoberta de fontes primárias inéditas. ${ }^{8}$ Não obstante a imensa

\footnotetext{
${ }^{7}$ A expressão indústria doméstica é utilizada por Vartuli (2012).

${ }^{8}$ São exemplos de trabalhos pioneiros que lidaram com fontes inéditas os de Leite (1982), Dias (1984), Silva (1984) e Rago (1985).
} 
construção de conhecimento sobre a história das mulheres no Brasil, desde meados de 1980, o imaginário popular ainda conserva, de modo geral, uma imagem bastante estereotipada das mulheres que viveram na América Portuguesa.

Mary Del Priore (1990, p. 19) reforça que a desigualdade entre os gêneros, constituída através da exploração ou escravização de mulheres por homens, contribuiu para a "fabricação de estereótipos bastante utilizados pela sociedade colonial e mais tarde incorporados pela historiografia”. RusselWood (1977, p. 1, tradução nossa) afirma ser inegável haver um pouco de verdade em cada um desses estereótipos, porém "a aceitação acrítica e a repetição por estudiosos tem ignorado o fato básico de que a fêmea (sic) fez parte de uma sociedade maior"’. Segundo o autor, nenhum outro aspecto histórico brasileiro recebeu um tratamento tão estereotipado quanto a posição da mulher e a sua contribuição para a sociedade e a economia da colônia:

A donzela branca e a senhora da Casa Grande foram descritas levando uma existência isolada, seja nos mais íntimos lazeres de seus lares ou em celas de conventos, imunes a duras realidades e a salvo de propostas ousadas de pretendentes. Sobre a mulher branca, dizia-se que, durante sua vida, deixava sua casa em apenas três ocasiões: para ser batizada, para ser desposada e para ser enterrada. O papel da mulher branca era visto como essencialmente passivo, vítima das exigências de um autoritário e frequentemente infiel marido mais velho para quem ela geraria filhos, ou vítima de um pai tirano. ${ }^{10}$ (RUSSELWOOD, 1977, p.1, tradução nossa)

Russel-Wood descreve também os papéis impostos às mulheres indígenas e às mulheres negras escravizadas, que recebiam um tratamento muito mais violento e desumanizador do que o reservado às mulheres brancas.

Quanto à mulher ameríndia (...), ela foi raramente descrita em qualquer papel além do de concubina ou de amante. A mulher negra e mulata (sic), escrava ou livre, tornou-se um símbolo de excitação sensual e satisfação sexual. Seu poder sobre o colono masculino branco foi louvado na mitologia popular, no verso e na prosa. Seus deveres domésticos estavam irrevogavelmente ligados ao seu papel sexual como o brinquedo dos filhos adolescentes, o alvo para a crueldade e o sadismo de esposas brancas ciumentas, ou o objeto de afetos do senhor da casa. ${ }^{11}$ (RUSSEL-WOOD, 1977, p. 1, tradução nossa)

\footnotetext{
${ }^{9}$ That there is some truth in each of these stereotypes is undeniable. But uncritical acceptance and repetition by scholars have ignored the basic fact that the female formed part of a larger society.

${ }^{10}$ The white donzela and the lady of the 'big house' have been depicted as leading a secluded existence, be it in the innermost recesses of their homes or in conventual cells, immune to harsh realities and safe from brash overtures by pretenders. Of the white woman, it was said, during her life time she left her home on only three occasions: to be baptized, to be married, and to be buried. The role of the white woman was seen as essentially passive, victim of the demands of an over-bearing and frequently unfaithful older husband to whom she would bear children, or of a martinet of a father.

${ }^{11}$ As for the Amerindian woman (...), she has rarely been depicted in any role other than that of concubine or lover. The black and mulatto woman, slave or free, became a symbol of sensual arousal and sexual fulfillment. Her power over the white male settler was lauded in popular mythology, verse, and prose. Her domestic duties were irrevocably
} 
Silva e Castilho (2014, p. 263) levantam uma questão importante que deve ser levada em conta no estudo desse período: "Será que se pode acreditar que todas as mulheres no período colonial eram iguais e viviam da mesma maneira?”. Fonseca-Silva (2012) faz uma belo estudo em que reúne mulheres de diversas etnias, nacionalidades e camadas sociais que desviaram dos estereótipos que compõem o imaginário colonial. Segundo a autora, entre os séculos XVI e XVIII, algumas esposas de donatários chegaram a governar capitanias hereditárias e a representar a coroa de Portugal na colônia "com plena autoridade tanto no campo judicial (para aplicar a lei) quanto no campo administrativo (para nomear funcionários)" (FONSECA-SILVA, 2012, p. 185), outras mulheres atuaram como bandeirantes ou sertanistas e houve até as que participaram de confrontos armados, inconfidências e revoltas. A resposta ao questionamento feito por Silva e Castilho é, portanto, não. Diante das variadas vivências que ocorreram em território brasileiro durante a América Portuguesa, é impossível aceitarmos a propagação de concepções errôneas que exageram, generalizam e mascaram a existência e a importância das mulheres neste período.

Nesse sentido, destaque-se o trabalho de Morais (2018), em que publica cartas de datas concedidas a várias mulheres em Jundiaí colonial. $\mathrm{O}$ fato de as terras serem concedidas pela administração pública às mulheres implica necessariamente em ressignificar o estereótipo da mulher restrita ao ambiente privado e doméstico.

Dias, já em 1983, escrevia sobre a necessidade de as mulheres serem vistas como "seres sociais, que integram sistemas de poder, redes de dominação e laços de vizinhança”, já que só assim poderemos "reconstruir a historicidade dos papéis femininos" e, um dia, realizar a "catarsis do conteúdo ideológico" (DIAS, 1983, p. 41).

\section{Descrição Diplomática}

O documento é iniciado pela titulação e nomeação do destinatário, identificado como "Senhor Licenciado Francisco Ioze de Souza". Licenciado era o termo utilizado para designar aquele que "no ato de Licenciatura tem recebido em alguma faculdade o grau, para a poder ensinar, como aprovado nela" ${ }^{12}$. Pode significar, também, aquele que foi "despedido de alguém"13, mas tendo em vista o

tied to her sexual role as the plaything of adolescent sons, the butt for the cruelty and sadism of jealous white wives, or the object of the affections of the master of the house.

12 BLUTEAU, Raphael. Vocabulario Portuguez e Latino. Lisboa: 1721, página 120. Disponível em: <http://200.144.255.59/catalogo_eletronico/imagemVerbete.asp?Verbete_Codigo=24844>. Acesso em: 17 de maio de 2019 . 
contexto enunciativo é possível assumir que se trata de um indivíduo detentor de certo grau de instrução ou pertencente a uma elevada classe social.

O corpo do documento é composto por uma notificação, por meio da qual Françisca notifica seu destinatário de lhe ter mandado "doze doblas" referentes ao pagamento da venda de dois escravos pertencentes a ela. $\mathrm{O}$ termo dobla refere-se a uma antiga moeda portuguesa e tem origem na língua castelhana $^{14}$. Além da notificação, há o dispositivo, no qual a autora expressa sua vontade de que a quantia seja entregue ao seu irmão, o "Coronel Joaquim Manoel da Silva e Castro", na cidade de São Paulo, por meio de um portador seguro, pois ela necessitaria realizar "certa arrumação". Em seguida, há uma espécie de despedida, contendo as fórmulas comuns de saudação como "Estimarei tenha Vossa Merce Saude" e "Deos o guarde muitos anõs". No protocolo final do documento, há as datações tópica e cronológica: "Sam Paulo 8 de Maio de 1791". Por fim, há a subscrição, a assinatura da autora: "Dona Françisca Maria Xavier de Castro" antecedida pelas fórmulas "De vossa mercê", "Muito venerada, e obrigada".

O quadro 1 a seguir dispões as estruturas diplomáticas da missiva.

Quadro 1 - Estrutura diplomática da missiva.

\section{Protocolo inicial:}

Senhor Licenciado Francisco Ioze de Souza [titulação, nomeação]

\section{Texto:}

As doze doblas que mandei digo que pedi a Vossa Merce re cebese do Cazal de escravos que vendi ao Tenente Coronel Paulino [notificação, exposição]

Vossa Merce me fará a onra, e favor remeter para esta cidade a entre gar a meu Jrmao Coronel Joaquim Manoel da Silva e Castro, por a[1] gum portador seguro, que necesito dellas para certa aruma çaõ. [dispositivo]

\section{Protocolo final:}

Estimarei tenha Vossa Merce Saude, e de me repetidas occazioẽs do Seu Servico, e Deos o guarde muitos anõs

\section{Sam Paulo [data tópica] 8 de Maio de 1791. [data cronológica]}

DE Vossa Merce Muito venerada, e obrigada Dona Françisca Maria Xavier de Castro [subscrição]

\footnotetext{
${ }^{13}$ No sentido de ser dispensado de suas obrigações por alguém. Por exemplo, "despedido da guerra" é usado para referenciar alguém que tenha sido dispensado após alistar-se.

${ }^{14}$ BLUTEAU, Raphael. Diccionario Castellano y Portuguez para facilitar a los curiosos la noticia de la lengua Latina, con el uso del Vocabulario Portuguez, y Latino. Lisboa: 1712, página 77.
} 
A espécie documental é uma carta, definida como "documento não-diplomático, mas de desenho mais ou menos padronizado" (BELLOTTO, 2002, p. 51). Quanto à tradição documental desta carta, trata-se de um original único "feito por direta vontade dos autores e conservado em matéria e formas genuínas sob as quais foi originalmente emitido" (PAOLI; REAL DIAZ, 1980 apud BELLOTTO, 2002, p. 106).

\section{Descrição Paleográfica}

O tipo de letra deste manuscrito pode ser classificado de forma genérica como humanística, com o qual "a maioria da documentação brasileira está registrada” (BERWANGER; LEAL, 2008, p. 68). Apesar das fronteiras bem definidas entre algumas letras, verificou-se um encadeamento entre outras, evidência de uma escrita cursiva e que proporcionava mais velocidade ao escriba.

O ductus da escrita - ou seja, "a ordem de sucessão e sentido dos traçados da letra" (CAMBRAIA, 2005, p. 24) - deste documento possui um traçado regular e de fácil leitura. É possível levantar a hipótese de que a autora possui certo grau de instrução, o que explicaria sua escrita hábil e homogênea. $\mathrm{O}$ módulo - isto é, a relação entre a largura e a altura da letra - utilizado é pequeno, com exceção das letras maiúsculas presentes em início de parágrafo, em nomes próprios, em patentes militares, em abreviaturas de formas de tratamento e em outros termos para os quais, provavelmente, a autora quis chamar atenção. É o caso de, por exemplo, Jrmao (1. 5) e Saude (1. 8). O ângulo da escrita — medido pela "relação entre os traços verticais das letras e a pauta horizontal" (CAMBRAIA, 2005, p. 24) - é bastante inclinado à direita, mas nada exagerado, pois não dificulta a leitura do documento. Quanto ao peso, definido como a relação entre traços finos e grossos, temos um peso médio e em alguns trechos observa-se um traço levemente mais forte, provavelmente engrossado devido ao maior volume de tinta desprendida à medida que a autora comprimiu a pena contra o suporte cartáceo.

Observaram-se abreviaturas ${ }^{15}$ por suspensão ou apócope em Senhor (1. 1), que (1. 2, 3 e 6) e Dona (1. 15) e por síncope com sobreposição de letras em Licenciado (1. 1), Vossa Merce (1. 2, 4, 8 e 13), Tenente (1. 3), Coronel (1. 3), para (1. 4 e 6), cidade (1. 4), Jrmao (1. 5), Joaquim (1. 5), Souza (1. 5), venerada (1. 14), Maria (1. 15) e Xavier (1. 15). O termo 'Coronel' não apresenta padronização,

\footnotetext{
${ }^{15}$ Em Abreviaturas: manuscritos dos séculos XVI ao XIX (2008, pp.12-14), Flexor define, agrupa e subdivide algumas formas de abreviaturas, siglas e notas tironianas que podem ser observadas em manuscritos. Neste trabalho, é feita a menção a abreviaturas por suspensão ou apócope, que é "quando falta o final da palavra" (p.14); a abreviaturas por contração ou por síncope, que é "quando faltam letras do meio do vocábulo" (p.14) e a abreviaturas com letras sobrescritas, "em que, em geral, é colocada a letra inicial ou prefixo da palavra, e, em suspensão, a última ou as últimas letras da palavra” (p.14).
} 
pois na terceira linha aparece abreviado por síncope e letras sobrescritas $\left(\right.$ Cor. $\left.^{\text {el) }}\right)$, enquanto na quinta linha está desenvolvido (Coronel). Há, ainda na quinta linha do documento, a seguinte abreviatura por síncope e sobreposição de letra da preposição "por": $\mathcal{C}^{\prime}$ (por). ${ }^{16}$

Foram identificados poucos casos de duplicação de consoantes, suas únicas ocorrências sendo 'll' e 'cc' em dellas (1. 6) e occazioẽs (1. 9). Observou-se também a presença de 's' caudado em posição final em occazioẽs (1. 9) e anõs (1. 10).

O uso de letras maiúsculas dá-se de modo variado, aparecendo em início de parágrafo, em vocábulos que indicam patentes militares, além de outras ocorrências como formas de tratamento, nomes próprios e substantivos comuns: Senhor Licenciado Francisco Ioze de Souza (1. 1), As (1. 2), a Vossa Merce (1. 2), Cazal (1. 3), Tenente Coronel Paulino (1. 3), Jrmao Coronel Joaquim Manoel da Souza e Castro (1. 5), Estimarei (1. 8). Ao final da missiva, há muitos casos de maiúsculas, como em Saude (1. 8), Seu Servico (1. 9), e Deos (1. 9), Sam Paulo (1. 11), Maio (1. 11), DE Vossa Merce (1. 13), Muito (1. 14) e Dona Françisca Maria Xavier de Castro (1. 15).

A divisão silábica não é assinalada pela autora com hífen ou duplo hífen e a edição semidiplomática respeita a opção gráfica da escriba. Isso é observável, por exemplo em re/cebese (1. 2 e 3), a entre/gar (1. 4 e 5), a[1]/gum (1. 5 e 6) e aruma/çaõ (1. 6 e 7). Os sinais de pontuação observados neste documento foram o ponto e a vírgula.

Quanto à acentuação gráfica no manuscrito, foi possível identificar marcas de nasalização indicadas por til ( ) em arumaçaõ (1. 7) e occazioẽs (1. 9). Em fará (1. 4) observou-se um acento agudo sobre a vogal da sílaba tônica, enquanto no nome próprio Ioze (1. 1) este acento está ausente. Há, ainda, algo que parece ser um acento na sílaba átona em anõs (1. 10), que se assemelha mais a uma marca de nasalização do que a um acento grave, mesmo apresentando uma forma menos curvada. Por esse motivo, esta marca foi transcrita com um til.

Ao escrever o 'd' minúsculo, a autora varia em sua forma: em mandei (1. 2), há um alongamento da haste que está ausente em outras palavras, tendo a seguinte aparência: $P$. Em Licenciado (1. 1), cidade (1. 4) e Saude (1. 8), o 'd' minúsculo aparece como , um alógrafo menos frequente que a forma . A autora também varia na forma do 'S' maiúsculo em posição inicial. Em Senhor (1.1) é grafado como $C$, enquanto em Souza (1.1 e 5), Saude (1. 8) e Seu Servico (1. 9) é grafado como. Em Sam Paulo (1.11) o mesmo grafema aparece como . Observou-se também que a autora utiliza o grafema 'J' em posição inicial na palavra Jrmao (1. 5).

\footnotetext{
${ }^{16}$ Para o desenvolvimento de abreviaturas, consultaram-se as obras de Nunes (1981) e de Flexor (2008)
} 
A seguir, no quadro 2, dispõem-se alguns exemplos de grafemas minúsculos e maiúsculos extraídos da carta. Informa-se que, para a melhor contextualização gráfica, optou-se em alguns casos por manter parte da palavra e não apenas o grafema isolado.

Quadro 2 - Alfabeto com exemplos de maiúsculas e minúsculas.

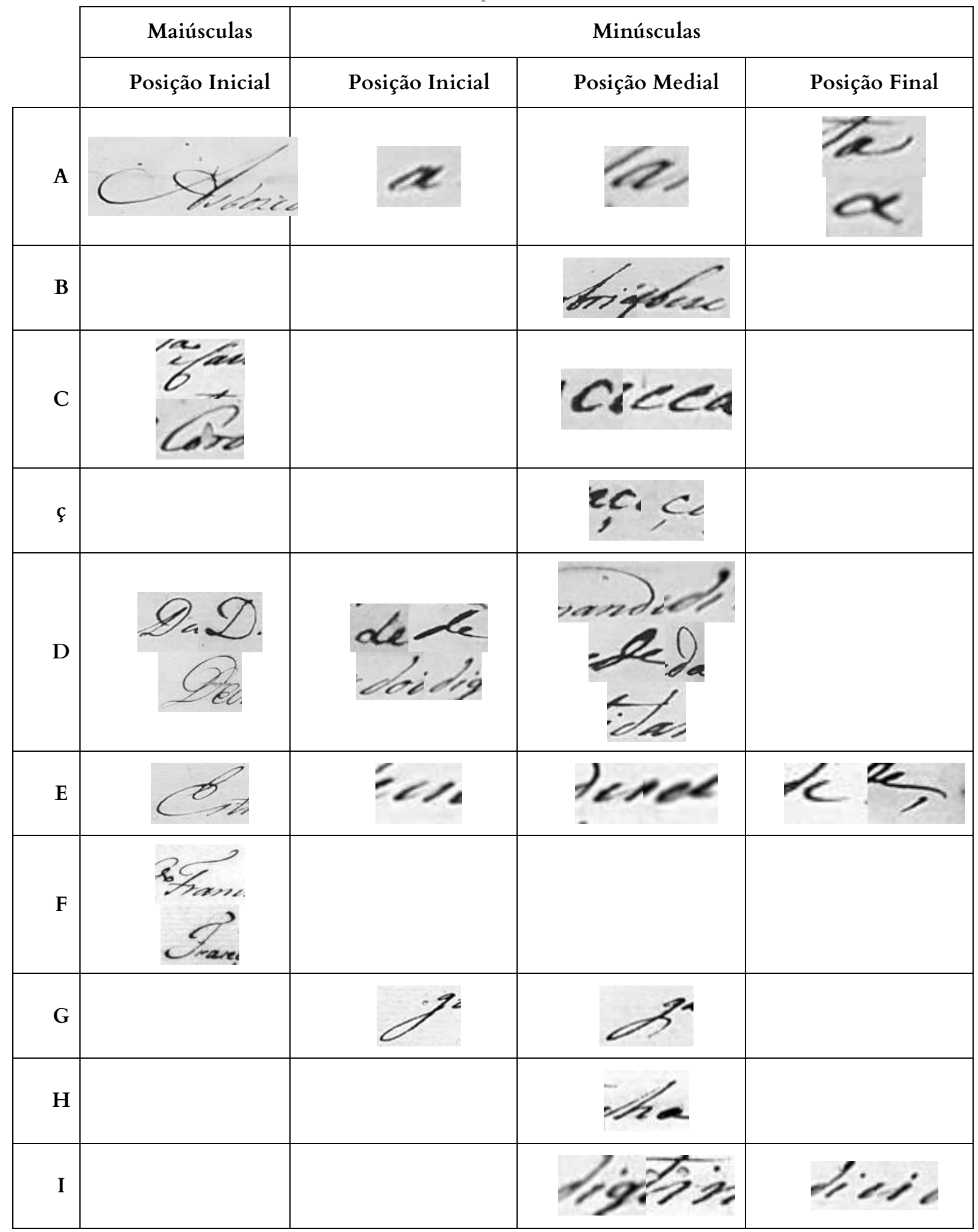




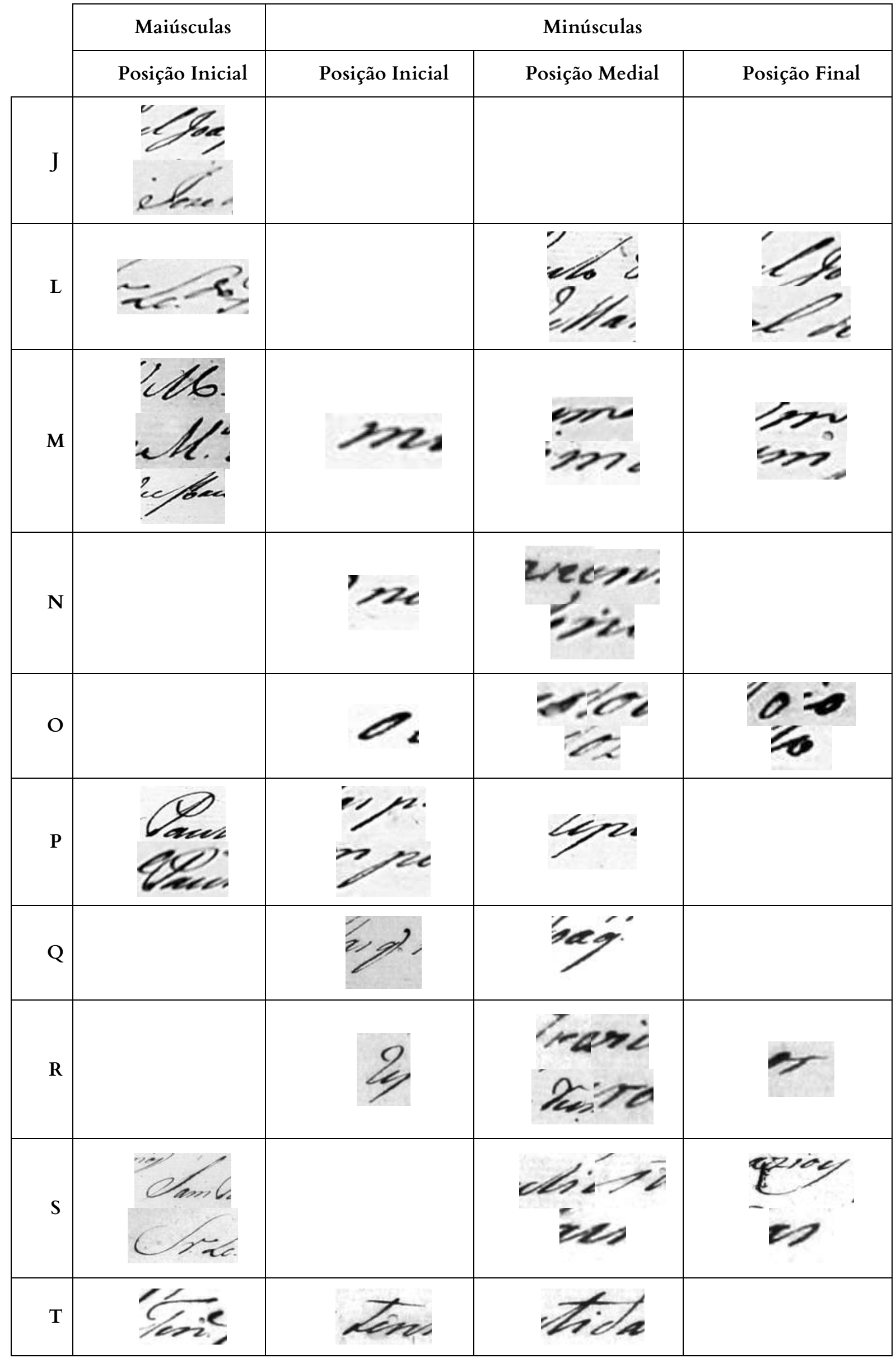




\begin{tabular}{|c|c|c|c|c|}
\hline & \multirow{2}{*}{$\begin{array}{c}\text { Maiúsculas } \\
\text { Posição Inicial }\end{array}$} & \multicolumn{3}{|c|}{ Minúsculas } \\
\hline & & Posição Inicial & Posição Medial & Posição Final \\
\hline $\mathbf{U}$ & & & 202 & ece \\
\hline V & Cinden & UD: 20 & Eos & \\
\hline$X$ & 2 & & & \\
\hline $\mathrm{Z}$ & & & $P 2 a$ & \\
\hline
\end{tabular}

O quadro 3 abaixo apresenta algumas abreviaturas utilizadas na missiva.

Quadro 3 - Relação de abreviaturas.

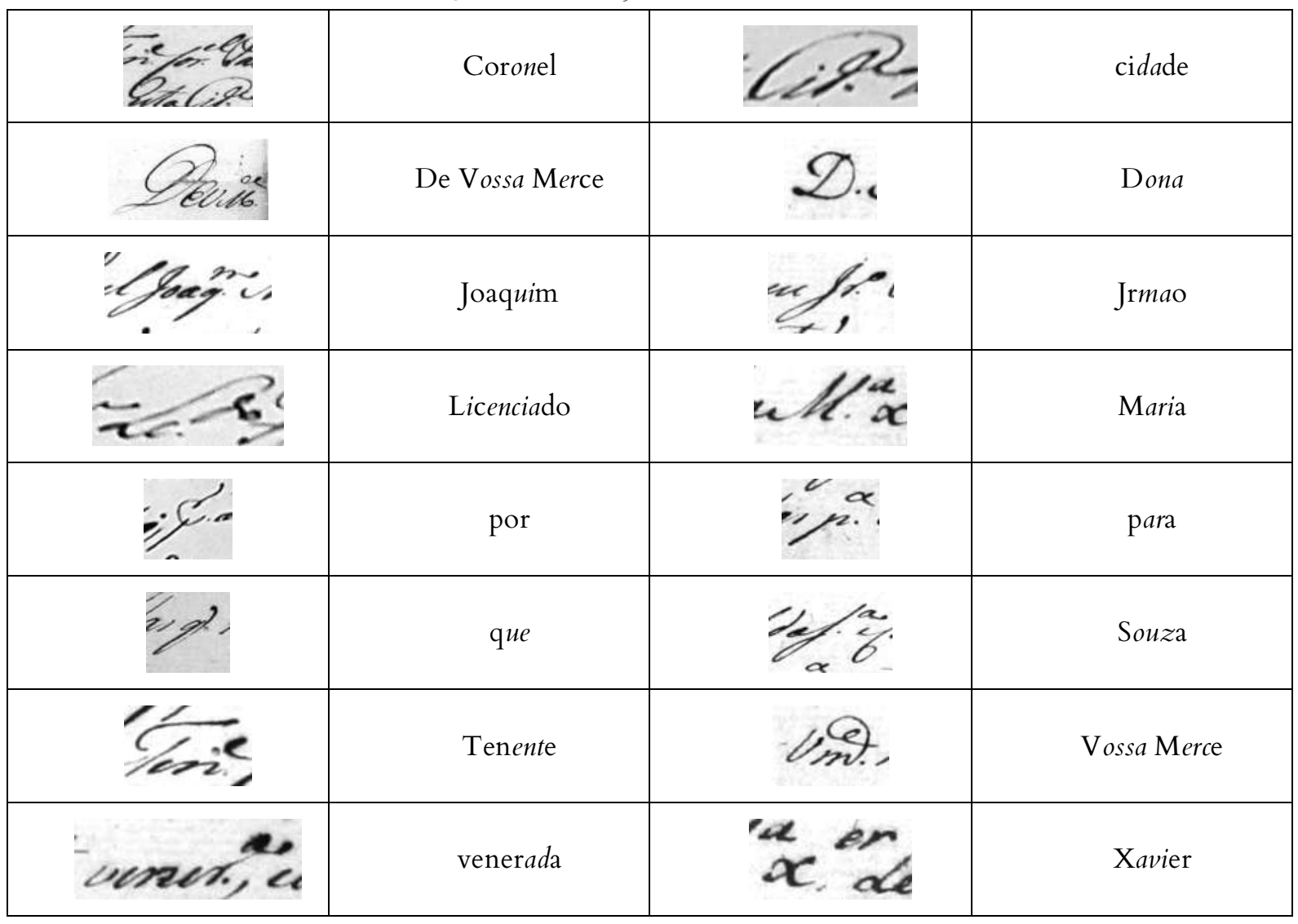




\section{Descrição codicológica ${ }^{17}$}

O presente documento encontra-se no Arquivo Público Estadual de São Paulo, na pasta de número 1.1.697, intitulada pelo APESP “Ofícios, ordens, requerimentos e certificados”. Apresenta como identificação o número '23' escrito em grafite cinza localizado no canto superior direito do fólio. Sua datação é do ano de 1791, explicitada ao final da carta como "8 de Maio de 1791". Há, também, escrito posteriormente em grafite cinza, o número '1791' no canto superior direito do fólio. Seu lugar de origem é São Paulo, informação encontrada no recto do primeiro fólio, ao final da carta, na linha 11, com a forma "Sam Paulo". Não há um fólio de abertura. O suporte material é papel (cartáceo) de cor amarelada clara. A distância entre as vergaturas é de $1 \mathrm{~mm}$, enquanto entre pontusais é de $20 \mathrm{~mm}$. Há uma filigrana que mede $10 \mathrm{~cm}$ x 7,6 cm ao centro do fólio, com os dizeres "FIN" e “1788" e entre eles três formas circulares distribuídas verticalmente. No interior da forma no topo há uma figura que se assemelha a uma cruz, e acima da mesma, há outra cruz. Ao redor das formas, é possível identificar dois adornos cujo formato se assemelha a asas.

Figura 1- Detalhe da marca d'água do documento.

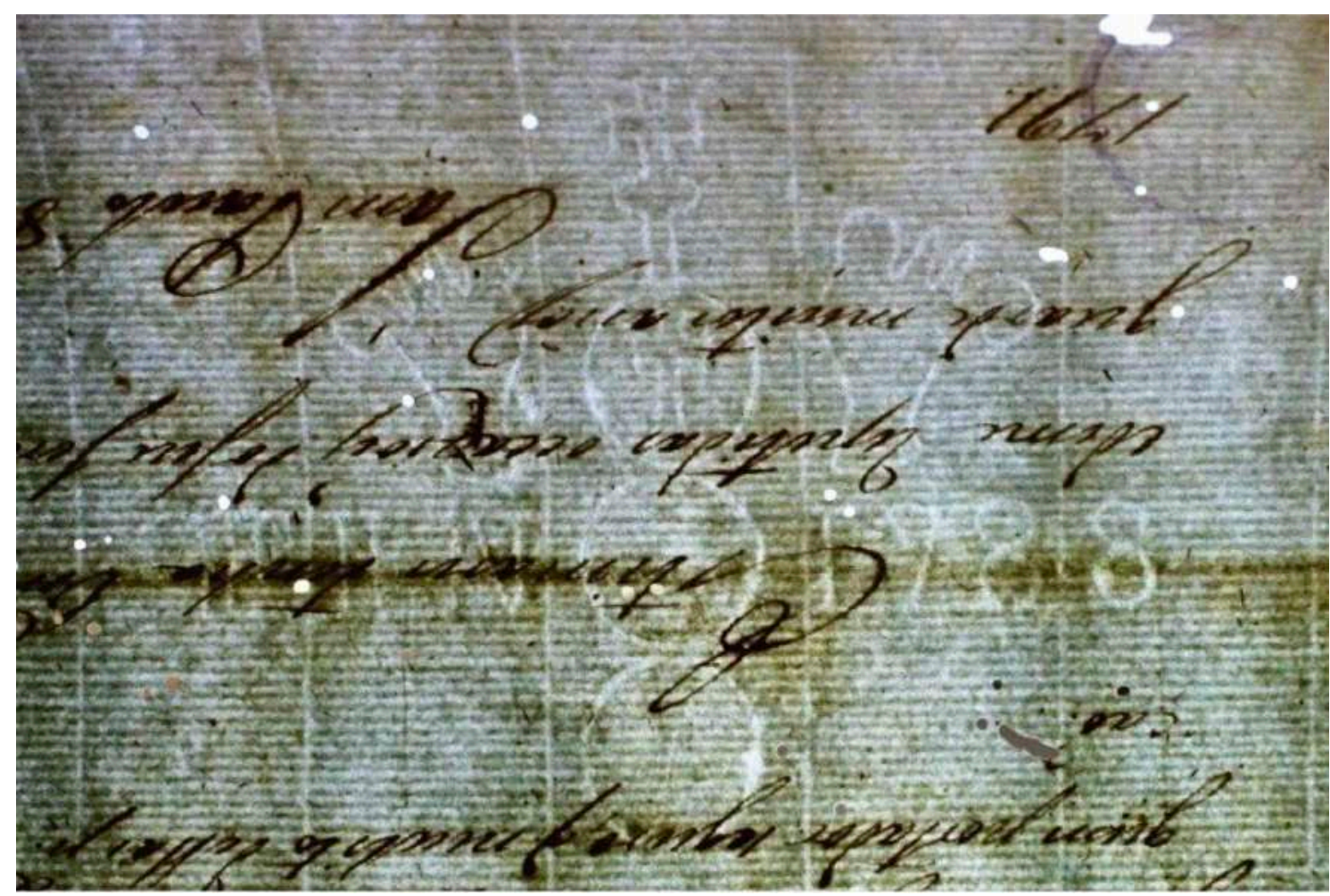

${ }^{17}$ A descrição codicológica aqui apresentada segue as orientações dispostas em Cambraia (2005) e aplicadas em Monte (2009). 
O documento é composto por dois bifólios dobrados ao meio. Somente o recto do primeiro fólio encontra-se escrito. A dimensão dos fólios é de $20,52 \mathrm{~cm}$ x 29,8 cm e a dimensão da mancha é de 17,6 cm x 29,8 cm. Há apenas uma coluna, com 15 linhas. O documento não apresenta pautas, numerações ou reclamos. Há apenas uma assinatura ao final do documento: "Dona Françisca Maria Xavier de Castro”. Não há capitulares ornamentadas e as únicas marcas especiais identificadas foram, além das intervenções em grafite já mencionadas, diversas marcas de papirófagos e um carimbo.

O carimbo tem formato circular, cor azulada e dimensão aproximada de 2,7 cm. Apresenta claramente os dizeres "Departamento do Arquivo do Estado de São". A partir da constatação de que há um grande espaço em branco após "São" e da análise de outros documentos que acompanham este, em cujos carimbos se lê sempre "Departamento do Arquivo do Estado de São Paulo", é possível conjecturar que a palavra "Paulo" está apagada devido a uma possível deterioração da tinta ou a uma falha mecânica do carimbo. Trata-se de um documento não encadernado e sem marcas de encadernação. Encontra-se dentro de uma pasta composta por mais de 100 outros documentos que variam entre si quanto a encadernação, dimensão, autores, assuntos, datas, locais, etc., mas que pertencem todos ao fundo da Secretaria de Governo de São Paulo.

\section{Normas técnicas utilizadas na transcrição}

\section{Edição Semidiplomática}

A transcrição que acompanha o fac-símile do documento é do tipo semidiplomática, situando-se entre uma transcrição interpretativa e uma transcrição diplomática. É marcada por um equilíbrio entre uma atitude conservadora e uma abordagem interpretativa. Caracteriza-se por uma intervenção moderada, cujo objetivo é eliminar certas dificuldades de leitura, por meio, por exemplo, do desenvolvimento de abreviaturas. Foram seguidas as seguintes normas técnicas estabelecidas pelo grupo de pesquisas Edição de Textos em Português $(\mathrm{ETeP})^{18}$ :

1. $[\mathrm{abc}]$ - Letra(s) / palavra(s) reconstituída(s) por conjectura.

2. Abreviaturas são desenvolvidas em itálico.

\footnotetext{
${ }^{18}$ As normas ainda não estão publicadas e foram desenvolvidas pelo líder do grupo de pesquisas ETeP (http://etep.fflch.usp.br/), Prof. Dr. Sílvio de Almeida Toledo Neto (FFLCH-USP).
} 
3. A grafia da parte desenvolvida segue a da variante (palavra ou segmento) desenvolvida mais recorrente no modelo.

4. A grafia da parte desenvolvida segue a grafia atual, se a forma (palavra ou segmento) nunca ocorre desenvolvida no modelo.

5. Paragrafação, grafia, pontuação e acentuação do modelo são fielmente reproduzidas.

6. Os alógrafos contextuais de caracteres são transcritos conforme o alfabeto atual. Exs.: $\varepsilon$ é transcrito como h; $\int$ é transcrito como s.

7. Os sinais de pontuação e de acentuação são uniformizados apenas quanto a sua variação caligráfica, preservando-se a mesma função que têm no modelo.

8. As fronteiras entre palavras são modernizadas conforme o modelo de separação vocabular atual ${ }^{19}$.

9. A transcrição é justalinear, com linhas numeradas de cinco em cinco à margem esquerda. Somente as linhas escritas são numeradas.

10. Espaçamento entre linhas: sempre 1,5 pt. Não deve haver linhas totalmente em branco na transcrição, mesmo que existam no modelo.

11. Os fólios ${ }^{20}$ são numerados da seguinte forma: $\| n .^{o}$ do fólio (1, 2 etc.) + lado do fólio (r. ou v. $\left.{ }^{21}\right) \|-$ O número inicia a primeira linha do fólio: $\| 1$ r.\|, $\|1 \mathrm{v}$.$\| , etc.$

\footnotetext{
${ }^{19} \mathrm{O}$ hífen não é usado entre pronome e verbo. Ex.: Declara sse. O apóstrofo não é usado quando há supressão de letras. Ex.: d agua.

${ }^{20}$ Fólio: cada uma das duas metades de um bifólio. Bifólio: unidade básica do caderno, constituída por uma peça retangular de pergaminho, papel, etc. dobrada ao meio para formar dois fólios.

${ }^{21}$ r. abrevia recto (página à direita) e v. abrevia verso (página à esquerda).
} 
12. Intervenções posteriores à redação do texto, escritas por outra mão, devem constar apenas em nota de rodapé, da seguinte forma: No local x (sobre a linha x, na margem x), há a seguinte anotação:...

13. Selos, sinais, carimbos devem ser descritos em nota de rodapé, quanto aos seguintes aspectos: medidas, cor da tinta, desenho e dizeres.

\section{Edição Modernizada}

Com o objetivo de uma melhor compreensão do assunto tratado no documento por um público não especializado, foi realizada uma edição modernizada da carta. Para este tipo de edição, foram adaptadas algumas normas técnicas da transcrição semidiplomática, além da modernização linguística:

1. Abreviaturas não são desenvolvidas em itálico para que a leitura tenha um efeito de maior fluência.

2. A grafia da parte desenvolvida segue a grafia atual.

3. Paragrafação, grafia, pontuação e acentuação do modelo são adaptadas conforme o uso atual para uma melhor compreensão.

4. As fronteiras entre palavras são modernizadas conforme o modelo de separação vocabular atual ${ }^{22}$.

5. A transcrição não é justalinear nem apresenta linhas numeradas de cinco em cinco à margem esquerda.

6. Erros evidentes no modelo são corrigidos.

${ }^{22} \mathrm{O}$ hífen é usado entre pronome e verbo. Ex.: Declara-se. O apóstrofo é usado quando há supressão de letras. Ex.: d'água. 
7. Todas as alterações necessárias para uma melhor leitura são feitas, incluindo a adaptação de preposições, artigos, pronomes, acentuação, pontuação, etc.

8. Deve ser compreendido que o público-alvo deste tipo de transcrição não conhece termos filológicos e não dispõe de um extenso material de pesquisa ao seu alcance. Portanto, tendo isto sempre em mente, foram adicionadas notas de rodapé que auxiliassem a compreensão de palavras pouco utilizadas e de difícil compreensão, como por exemplo, "dobla".

9. A estrutura do gênero textual do documento é preservada. 


\section{Fac-símile}

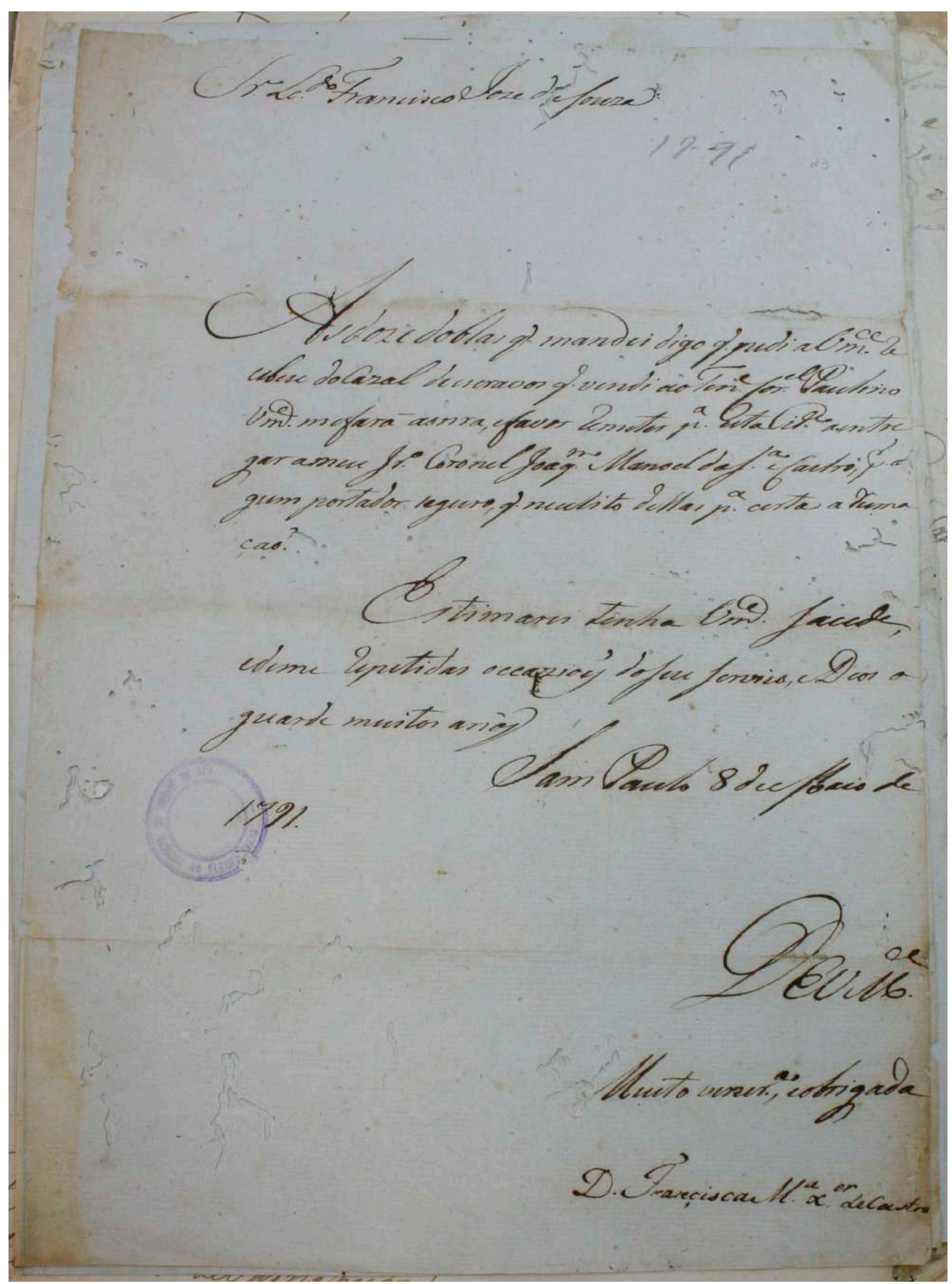




\section{Edição Semidiplomática}

"|1r.|| Senhor Licenciado Francisco Ioze de Souza 2324

As doze doblas que mandei digo ${ }^{25}$ que pedi a Vossa Merce re cebese do Cazal de escravos que vendi ao Tenente Coronel Paulino Vossa Merce me fará a onra, e favor remeter para esta cidade a entre

5 gar a meu Jrmao Coronel Joaquim Manoel da Silva e Castro, por a[1] ${ }^{26}$ gum portador seguro, que necesito dellas para certa aruma çaõ.

Estimarei tenha Vossa Merce Saude, e de me repetidas occazioẽs do Seu Servico, e Deos o

10 guarde muitos anõs

$1791 .^{27}$

Sam Paulo 8 de Maio de

DE Vossa Merce

Muito venerada, e obrigada

Dona Françisca Maria Xavier de Castro

\footnotetext{
${ }^{23}$ Este documento pertence ao fundo da Secretaria de Governo da Capitania de são Paulo, do Arquivo Público do Estado de São Paulo, tem a cota APESP-23 e encontra-se na pasta identificada como 1.1.697.

${ }^{24}$ Entre a primeira e a segunda linha há, escrito em grafite cinza, o seguinte número: 1791.

25 "Digo" é um verbo frequentemente utilizado durante a escrita de manuscritos para a correção de palavras imediatamente antecedentes sem que sejam necessárias rasuras.

${ }^{26}$ Letra ilegível por fragmentação material e reconstituída por conjectura.

${ }^{27}$ Localizado na margem esquerda há um carimbo circular de cor azul com os seguintes dizeres: "DEPARTAMENTO DO ARQUiVo DO ESTADO DE SÃO". A partir da constatação de que há um grande espaço em branco após "SÃO" e da análise de outros documentos que acompanham este, em cujos carimbos se lê "Departamento do ARquivo do Estado De SÃo PAUlo", é possível conjecturar que a palavra "PAULO" encontra-se apagada devido a uma possível deterioração da tinta ou a uma falha mecânica do carimbo.
} 


\section{Edição Modernizada}

Senhor Licenciado ${ }^{28}$ Francisco José de Souza,

As doze doblas ${ }^{29}$ que mandei, digo, que pedi a Vossa Mercê que recebesse do casal de escravos que vendi ao Tenente Coronel Paulino, Vossa Mercê me fará a honra e o favor de remeter para esta cidade para entregar ao meu irmão, o Coronel Joaquim Manoel da Silva e Castro, por algum portador seguro, porque necessito delas para certa arrumação.

Estimarei que tenha Vossa Mercê saúde, e dê-me repetidas ocasiões do seu serviço, e que Deus o guarde por muitos anos.

São Paulo, 8 de maio de 1791.

De Vossa Mercê,

Muito venerada e obrigada,

Dona Françisca Maria Xavier de Castro.

${ }^{28}$ Licenciado era o nome usado para identificar a pessoa que tinha um grau universitário e estava autorizado para ensinar.

${ }^{29}$ Dobla é o nome de uma antiga moeda portuguesa, feita de ouro puro. 


\section{Considerações finais}

Em 8 de maio de 1791, Françisca Maria Xavier de Castro escreve uma carta por meio da qual pede a entrega de uma quantia de doze doblas ao irmão, para fazer uma arrumação. Este ato implica no fato de Françisca possuir um grau de responsabilidade no âmbito da administração econômica familiar. O ductus de traçado regular e de fácil leitura, o módulo pequeno e homogêneo, o ângulo inclinado à direita e o peso médio da escrita (demonstrando um controle do volume de tinta a ser desprendido da pena contra o suporte) são pistas que ajudam a construir a hipótese de que a autora, ao apresentar uma escrita hábil, possuía certo grau de instrução, além de escrever com certa frequência. $O$ fato de Françisca ser uma mulher alfabetizada no contexto da Capitania de São Paulo, no século XVIII, também levanta diversas possibilidades e reflexões acerca de seu status social. Retornamos ao texto de Vartuli (2012), mencionado na introdução deste artigo. Apesar das exigências de um discurso educativo oficial de que as mulheres fossem "educadas" para serem nada mais do que mães e esposas, algumas exerceram atividades que extrapolavam as diretrizes desses discursos:

Ao travarem contato com a cultura escrita, essas mulheres ampliaram seus círculos de convívio e atuação, como a presença decisiva na administração da indústria doméstica, e redefiniram, assim, os caminhos do viver em colônia e da própria estrutura colonial. (VARTULI, 2012, p. 37)

A imagem de uma mulher enclausurada em seu lar, submissa ao marido ou ao pai, desprovida de funções, responsabilidades ou qualquer influência na administração econômica familiar não corresponde, portanto, à nossa autora.

Diante do apagamento historiográfico da importância das mulheres na composição da sociedade colonial e da reprodução contínua e incessante dos estereótipos femininos, são imprescindíveis os estudos que evidenciem a presença das mulheres na América Portuguesa. Esse trabalho de prospecção documental, lento e sistemático, realizado no âmbito do Projeto M.A.P. é capaz de fazer reviver documentos esquecidos em meio a tantos outros. O rigor da Filologia coloca em relevo tanto a materialidade quanto a substância documental. E é precisamente esse rigor que faz com que possamos, de forma fidedigna, nomear mulheres, que não são geralmente referidas por seus nomes próprios, e recontar as histórias que os fragmentos registrados em papel fazem chegar até nós. Daí a importância de publicarmos edições conservadoras e também modernizadas, já que é importante dar a conhecer essa história a um público não treinado na leitura de manuscritos. Sabemos, no entanto, que o imenso silêncio documental também é revelador do papel marginal e colonizado que foi relegado à mulher desde os tempos da América Portuguesa. 


\section{Referências bibliográficas}

Arquivo Público do Estado de São Paulo. Secretaria de Governo da Capitania de São Paulo. Guia do Acervo do Arquivo Público do Estado de São Paulo. Disponível em: $<$ http://icaatom.arquivoestado.sp.gov.br/ica-atom/index.php/secretaria-de-governo-dacapitania-de-sao-paulo-2>. Acesso em: 5 de junho de 2019.

Arquivo Público do Estado de São Paulo. Unidade de instalação 1.1.697-1.1.699 - Ofícios, ordens, requerimentos e certificados. Guia do Acervo do Arquivo Público do Estado de São Paulo. Disponível em: <http://icaatom.arquivoestado.sp.gov.br/ica-atom/index.php/oficiosordens-requerimentos-e-certificados;isad>. Acesso em: 17 de maio de 2019.

BELLOTTO, Heloísa Liberalli. Como fazer análise diplomática e análise tipológica de documento de arquivo. vol. 8. São Paulo: Arquivo do Estado e Imprensa Oficial do Estado, 2002.

BERWANGER, Ana Regina; LEAL, João Eurípedes Franklin. Noções de Paleografia e de Diplomática. 3. ed. Santa Maria: Editora Ufsm, 2008.

BLUTEAU, Raphael. Diccionario Castellano y Portuguez para facilitar a los curiosos la noticia de la lengua Latina, con el uso del Vocabulario Portuguez, y Latino. Lisboa: 1712.

BLUTEAU, Raphael. Vocabulario Portuguez e Latino. Lisboa: 1721.

CAMBRAIA, César Nardelli. Introdução à crítica textual. São Paulo: Martins Fontes, 2005.

DIAS, Maria Odila Leite da Silva. Mulheres sem História. Revista de História, n. 114, p. 31-45, 7 jun. 1983.

DIAS, Maria Odila Leite da Silva. Quotidiano e poder em São Paulo no século XIX. São Paulo: Brasiliense, 1984.

FLEXOR, Maria Helena Ochi. Abreviaturas: manuscritos dos séculos XVI ao XIX. 3. ed. Rio de Janeiro: Arquivo Nacional, 2008.

FONSECA-SILVA, Maria da Conseição. Memória, mulher e política: do governo das capitanias à presidência da república, rompendo barreiras. In: TASSO, Ismara; NAVARRO, Pedro, orgs. Produção de identidades e processos de subjetivação em práticas discursivas. Maringá: Eduem, 2012. pp. 183-208.

LEITE, Miriam Lifchtz Moreira. A mulher no Rio de Janeiro no século XIX. São Paulo: Fundação Carlos Chagas, 1982.

MONTE, V. Uma descrição codicológica: documentos setecentistas. Filologia e Linguística Portuguesa, n. 10-11, p. 103-120, 2009. 
MORAIS, Kathlin Carla de. 'Damos aos suplicantes os chãos que pede': edição fac-similar e semidiplomática e estudo do manuscrito Cartas de Datas de Jundiaí do século XVII. 2018. 329 f. Dissertação (Mestrado) - Curso de Faculdade de Filosofia, Letras e Ciências Humanas, Filologia e Língua Portuguesa, Universidade de São Paulo, São Paulo, 2018.

NUNES, Eduardo Borges. Abreviaturas paleográficas portuguesas. 3. ed. Lisboa: Fl, 1981.

PAIXÃO DE SOUSA, M. C.; MONTE, V. M. do et al. Projeto M.A.P. (Mulheres na América Portuguesa): Mapeamento de escritos de mulheres e sobre mulheres no espaço atlântico português a partir de métodos das Humanidades Digitais. Disponível em: <http://nehilp.prp.usp.br/ nehilp/HD/MAP/>. Acesso em: 17 de maio de 2019.

PRIORE, Mary del. Ao sul do corpo: condição feminina, maternidades e mentalidades no Brasil Colônia. 1990. 294 f. Tese (Doutorado) - Curso de Faculdade de Filosofia, Letras e Ciências Humanas, História, Universidade de São Paulo, São Paulo, 1993.

RAGO, Margareth. Do cabaré ao lar: A utopia da cidade disciplinar, 1890-1930. Rio de Janeiro: Paz e Terra, 1985.

RUSSELL-WOOD, Anthony John R.. Women and Society in Colonial Brazil. Journal Of Latin American Studies. Grã-bretanha, p. 1-34. maio 1977.

SILVA, Maria Beatriz Nizza da. Sistema de casamentos no Brasil colonial. São Paulo: TA Queiroz/Edusp, 1984.

SILVA, Letícia Ferreira da; CASTILHO, Maria Augusta de. Brasil Colonial: As mulheres e o imaginário social. Cordis: Revista Eletrônica de História Social da Cidade, São Paulo, n. 12, p.257-279, jan./jun. 2014.

VARTULI, Silvia Maria Amâncio Rachi. Senhoras da Colônia: Cultura escrita e inserção feminina em Minas Gerais. Cadernos de História, Belo Horizonte, v. 13, n. 18, p.32-63, $1^{\text {o }}$ sem, 2012.

WOLFF, Cristina Scheibe; POSSAS, Lidia M. Vianna. Escrevendo a história no feminino. Estudos Feministas, Florianópolis, v. 13, n. 3, p.585-589, set./dez. 2005. 